\title{
Metabolic Disorders in Nigerians Occupationally Exposed to Cement Dust
}

\author{
Moses Akiibinu (PhD) \\ Mary Adeyemi (MSc) \\ Toyosi Ogunbiyi (BSc) \\ Mojirade Amusah (BSc)
}

Department of Biochemistry and Chemistry,

Caleb University Lagos, Nigeria

Adeolu Amusan (BSc)

Department of Chemical Pathology and Immunology,

Olabisi Onabanjo University, Ago-Iwoye Ogun state, Nigeria

John Anetor (PhD)

Department of Chemical Pathology, University of Ibadan, Ibadan, Nigeria

doi: 10.19044/esj.2016.v12n33p57 URL:http://dx.doi.org/10.19044/esj.2016.v12n33p57

\begin{abstract}
Exposures to cement dust have been linked with lung dysfunctions in some occupationally exposed workers. There is a dearth of information on the potentials of the cement particles to induce tumorigenesis, kidney failure and oxidative stress in the exposed workers. This study assessed the effects of cement exposure on macrophage activation, tumor markers, kidney injury molecule- 1 and markers of oxidative stress in cement loaders with prolonged exposures. Twenty-nine male workers who had direct exposure to cement dust and gases for a period of 2-30 years in Elephant / Lafarge cement depot Ibadan, Nigeria, were recruited for this study. Another twenty apparently healthy individuals who had no interaction with cement served as controls. Levels of carcino-embryonic antigen (CEA), alpha fetoprotein (AFP), kidney injury molecule-1 (KIM-1), DNA-8-hydroxyguanosine (8-OHdG), neopterin, total plasma peroxide (TPP), total antioxidant potential (TAP), oxidative stress index (OSI), malondialdehyde (MDA) and albumin were determined in all participants using ELISA and spectrophotometry methods respectively. The result shows significantly $(\mathrm{p}<0.05)$ higher levels of $8-\mathrm{OHdG}$, neopterin, TPP, OSI, MDA, CEA and KIM-1 in cement exposed workers when compared with controls. Cement exposed workers demonstrated a significantly $(\mathrm{p}<0.05)$ lower level of TAP in cement exposed workers when compared with controls. There were insignificant $(\mathrm{p}>0.05)$ changes observed
\end{abstract}


in the plasma levels of albumin and AFP when compared with the controls. No significant $(\mathrm{p}>0.05)$ correlations could be observed between the levels of 8-OHdG, neopterin, albumin, MDA, CEA, AFP, KIM-1 and OSI in the cement exposed workers.

Metabolic disorders including excessive macrophage activation, oxidative DNA damage, kidney diseases and chemically-induced tumors are imminent in cement exposed workers.

Keywords: Cement, metabolic changes, workers

\section{Introduction}

Cement dust contains 60-67\% calcium oxide, 17-25\% silicon oxide, 3-5\% aluminium oxide, with some amount of iron oxide, potassium, sodium, sulphur, magnesium oxide, cobalt, chromium (Fell et al, 2003), heavy metals like nickel, lead, mercury, other chemicals like dioxins, PAHs, benzene, and polychlorinated biphenyls and particulate matters (Baby et al, 2008). The dust has a diameter ranging from 0.05 to $5.0 \mu$ (Kalacic, 1973; Abrons et al, 1997) emitted in form of particulate matters or aerosol, which degrade the air quality and create considerable environmental pollution (Adak et al, 2007). The emitted gases and particulate matters or aerosols of cement can be ingested or inhaled (Green, 1970).

Exposure to cement dust for a short period may not cause serious problems. However, reports show that prolonged exposure to toxic contents of cement (i.e. heavy metals) can cause severe irreversible damage to plants and animals through inhibition of enzymes, interference with normal metabolic pathways and precipitation in vital organs (Heather, 2003). Among the constituents of cement, hexavalent chromium is a potential human carcinogen while Haber-Weiss reaction with fiber surface iron produces free radicals (Koh et al, 2011). Pournourmohammadi et al. (2008) reported significantly higher levels of $\mathrm{Al}$ and $\mathrm{Cr}$ in direct cement-exposed workers. Circulating inhaled Cr (VI) if trapped in vital organs such as kidney and liver, exerts toxic effects via generation of free radicals and inflammatory responses. Ikli et al. (2003) reported that in organs like kidneys, skin and liver, cellular activation in response to the particulate matters can lead to inflammatory responses and excessive production of reactive oxygen species. However, respiratory diseases in long-term cement dust exposure have been associated with irritation of the exposed mucous membranes (Schwartz, 1994; Sivicommar et al, 2001; Zeleke et al, 2010). It is evident that inhaled cement particles cause activation of alveolar macrophages, mesothelial cells and lung fibroblasts, leading to high free radical generation and enhanced inflammatory cytokine production in cement exposed workers (Zeleke et al, 2010). 
Due to unemployment and lack of adequate machineries, some able bodied men have chosen cement loading as their main source of income, without using any protective devices. The present study was designed to investigate the potential carcinogenicity, oxidative stress effects and the ability of cement particles to induce renal dysfunction in the exposed workers, by determining the levels of carcino-embryonic antigen (CEA), alpha fetoprotein (AFP), kidney injury molecule1 (KIM-1), DNA-8-OHguanosine (8-OHdG), neopterin, total plasma peroxide (TPP), total antioxidant potential (TAP), oxidative stress index (OSI), malondialdehyde (MDA) and albumin were determined in these occupationally exposed workers and controls.

\section{Materials and Methods \\ Materials}

Twenty nine cement loaders in the Elephant / Larfage Cement Depot, Ibadan volunteered to participate in this study. These cement loaders had no protective devices and they had direct contact with cement dust and gases. Another twenty apparently healthy individuals who had no interaction with cement served as controls. The body weight and height of participants were taken, and the body mass index (BMI) calculated.

This study was approved by the Institutional Review Board, and informed consent obtained from all participants before the commencement of the study. Five (5) $\mathrm{ml}$ of fasting blood sample was collected from each participant into lithium heparin bottle, centrifuged and the plasma stored at $20^{\circ} \mathrm{C}$ until ready for analysis. Also, $5 \mathrm{ml}$ of urine was collected for the determination of KIM-1.

\section{Methods}

\section{Determination of plasma 8-OHdG:}

8-OHdG was determined by using commercially prepared enzyme linked immunosorbent assay (ELISA) kits. The principle is based on the fact that a monoclonal antibody specific to 8-OHdG pre-coated onto a microplate undergoes a competitive inhibition reaction between 8-OHdG in the standard and plasma samples. Avidin conjugated to Horseradish Peroxidase (HRP) is made to react with the complex which produces color after addition of the substrate solution, the intensity of the color developed is inversely proportional to the concentration of 8-OHdG in the sample.

\section{Determination of plasma CEA and AFP}

CEA and AFP were determined by using commercially prepared enzyme linked immunosorbent assay (ELISA) kits (cat. numbers 1110010 and 1107029 respectively) by InterMedical S.R.I. Villanicca (NA) Italy. 
Briefly, an aliquot of the plasma (at room temperature) was incubated with enzyme conjugate (corresponding monoclonal antiserum-antibody conjugated with horseradish peroxidase) in the microtiter wells coated with corresponding monoclonal antibody, directed towards a unique antigenic site of either CEA or AFP. After incubation, the unbound conjugate was washed off, the wells drained and the substrate solution added for color development. Sulphuric acid was later added to stop the reaction. The intensity of the color corresponding to the concentration of the analyte was read at $450 \mathrm{~nm}$ with TECO microplate reader, USA).

\section{Determination of MDA}

Level of lipid peroxidation was determined in both cement exposed workers and controls by measuring the formation MDA using the method of Varshney and Kale (1990). The principle is based on the fact that malondiahydehyde (MDA) produced from the peroxidiation of membrane fatty acid reacts with the chromogenic reagent; 2-thiobarbituric acid (TBA) under acidic conditions to yield a pink-colored complex measured spectrophotometrically at 532nm. 1, 1, 3, 3-tetramethoxylpropane was used as standard.

\section{Determination of TAP}

TAP was determined in both cement exposed workers and controls using the ferric reducing / antioxidant power (FRAP) assay (Benzie et al, 1996; Harma et al, 2005). $1.5 \mathrm{ml}$ of working pre-wormed $\left(37^{0} \mathrm{C}\right)$ FRAP reagent $\left(300 \mathrm{mM}\right.$ acetate buffer - ${ }_{\mathrm{p}} \mathrm{H}-3.6,10 \mathrm{mM}$ 2,4,6- tripyridyl-s-triazine in $40 \mathrm{mM} \mathrm{HCl}$ and $20 \mathrm{mM} \mathrm{FeCl}_{3}$ at ratio 10:1:1) was vortex mixed with $50 \mu \mathrm{l}$ of test sample and standards. Absorbance was read at $593 \mathrm{~nm}$ against a reagent blank. The result was reported as $\mu$ mol Trolox equiv. / L.

\section{Determination of total plasma peroxide (TPP)}

Determination of TPP was based on the principle that ferrousbutylated hydroxytoluene-xylenol orange complex reacts with plasma hydrogen peroxide to form a colour complex measured spectrophotometrically at $560 \mathrm{~mm}$. $\mathrm{H}_{2} \mathrm{O}_{2}$ was used as standard. $1.8 \mathrm{ml}$ of reagent 6 (F0X2) was mixed with $200 \mu 1$ of plasma. This was incubated at room temperature for 30 minutes. $100 \mu \mathrm{Mol} \mathrm{H}_{2} \mathrm{O}_{2}$ was used as standard. The mixture was centrifuged and the supernatant separated for reading at 560nm (Benzie et al, 1996).

\section{Determination of oxidative stress index (OSI)}

OSI, an indicator of the degree of oxidative stress is the percent ratio of the TPP to the TAP (Benzie et al, 1996). 


\section{Determination of albumin}

Principle: The measurement of serum albumin is based on its quantitative binding to the indicator 3,3, ``,5- tetrabromo-cresol sulphtalein or bromocresol green (BCG). The albumin-BCG-complex absorbs maximally at $578 \mathrm{~nm}$, the absorbance being directly proportional to the concentration of the albumin in the sample.

\section{Statistical analysis}

All statistical analyses were performed using Statistical Package for Social Sciences (SPSS), version 15.0. The data were expressed as Mean \pm SD. Student (t) test was used for comparison of cement exposed workers and controls. Pearsonian correlation coefficient (r) was calculated. $P$ values less than 0.05 were considered significant.

\section{Results}

In the cement exposed workers, significantly $(\mathrm{p}<0.05)$ higher plasma levels of 8-OHdG, neopterin, TPP, OSI, MDA, CEA and urinary KIM-1, with a significantly $(\mathrm{p}<0.05)$ lower level of TAP (Tables 2 and 3 ) were observed when compared with controls. There were no significant $(p>0.05)$ changes in the plasma levels of albumin and AFP in the cement loaders when compared with the controls. There was no significant $(\mathrm{P}>0.05)$ relationship when OSI was correlated with levels of 8-OHdG, neopterin, albumin, CEA, AFP, KIM-1 in the cement loaders (Table 4).

Table 1: Physical Characteristics of Cement Loaders and Controls

$$
\text { Controls }
$$

Cement Loaders p-values

\begin{tabular}{lcll} 
Age (years) & $46.17 \pm 15.03$ & $51.76 \pm 8.81$ & 0.217 \\
Weight $(\mathrm{kg})$ & $69.56 \pm 9.84$ & $66.62 \pm 11.93$ & 0.376 \\
Height $(\mathrm{M})$ & $1.68 \pm 0.07$ & $1.69 \pm 0.07$ & 0.703 \\
BMI $\left(\mathrm{Kg} / \mathrm{M}^{2}\right)$ & $24.64 \pm 3.54$ & $22.89 \pm 3.38$ & 0.187 \\
\hline
\end{tabular}

Table 2: Plasma levels of Albumin and Markers of Oxidative Stress in Cement Loaders and Controls

\begin{tabular}{llll}
\hline & Controls & Cement Loaders & p-values \\
\hline Albumin $(\mathrm{g} / \mathrm{dl})$ & $3.50 \pm 1.2$ & $3.53 \pm 1.29$ & 0.785 \\
TPP $\left(\mu \mathrm{mol} / \mathrm{L} . \mathrm{H}_{2} \mathrm{O}_{2}\right)$ & $11.8 \pm 1.1$ & $14.6 \pm 1.3$ & $<0.010^{*}$ \\
TAP $(\mu \mathrm{MolTroloxEquiv./L)}$ & $1522 \pm 209$ & $1301 \pm 186$ & $<0.001^{*}$ \\
OSI $(\%)$ & $0.65 \pm 0.2$ & $1.1+0.4$ & $<0.001^{*}$ \\
MDA $(\mathrm{nMol} / \mathrm{ml})$ & $3.8 \pm 1.6$ & $6.3 \pm 2.1$ & $<0.001^{*}$ \\
\hline \multicolumn{2}{r}{}
\end{tabular}


Table 3: Plasma levels of DNA 8-OHG, KIM-1, Neopterin and Tumor Markers in Cement Loaders and Controls

\begin{tabular}{llll}
\hline & Controls & Cement Loaders & p-values \\
\hline 8-OHdG $(\mathrm{ng} / \mathrm{ml})$ & $83.7 \pm 21.6$ & $134.0 \pm 28.7$ & $0.045^{*}$ \\
KIM-1 $(\mathrm{pg} / \mathrm{ml})$ & $202 \pm 133$ & $426 \pm 152$ & $<0.01^{*}$ \\
CEA(ng/ml) & $1.2 \pm 1.0$ & $4.5 \pm 3.2$ & $0.022^{*}$ \\
AFP $(\mathrm{ng} / \mathrm{ml})$ & $9.7 \pm 5.9$ & $10.8 \pm 6.6$ & 0.644 \\
Neopterin $(\mathrm{nMol} / \mathrm{ml})$ & $8.4 \pm 3.0$ & $16.5 \pm 5.0$ & $<0.01^{*}$ \\
\hline & *=significantly different from controls. &
\end{tabular}

Table 4: Correlation between the levels of 8-OHdG, neopterin, CEA, AFP and KIM-1 and OSI in Cement loaders $(\mathrm{N}=29)$

\begin{tabular}{lll}
\hline Groups & r-values & p-values \\
\hline Albumin / OSI & 0.15 & 0.36 \\
8-OHdG / OSI & 0.27 & 0.15 \\
KIM-1/ OSI & 0.28 & 0.11 \\
CEA / OSI & 0.18 & 0.33 \\
AFP/ OSI & 0.06 & 0.74 \\
Neopterin / OSI & 0.32 & 0.08 \\
\hline
\end{tabular}

\section{Discussion}

Cement contains various inhalable and ingestible potentially toxic agents. Larger percent of dried aerosols of cement with particles less than $0.5 \mu$ can diffuse easily through the lungs into the circulation (Valavanidis et al, 2008), while particles larger than $5 \mu$ cannot penetrate the alveoli but get deposited in the lungs to cause irritation and inflammation. Since particles of cement dust have diameter ranging from 0.05 to $5.0 \mu$ (Kalacic, 1973; Abrons et al, 1997), a larger proportion would penetrate the alveoli to the blood circulatory system. Available report shows that acutely inflamed or irritated lungs absorb particles rapidly than normal lungs (George et al, 1950). The absorbed cement particles including $\mathrm{Cr}$ and $\mathrm{Fe}$ are capable of generating ROS via Fenton or Fenton-like reactions (Shi et al, 1993; Torreilles \& Guerin, 1990). These and other factors could enhance cellular activation and higher plasma levels of TPP, MDA and 8-OHdG observed in our cement exposed workers. Our findings agree with the reports of previous workers (Afaq and Abidi, 2000; Kopnin et al, 2004; Dopp et al, 2005) who reported that alveolar macrophages and other cells in the lungs generate reactive oxygen species in response to cement particles and products.

Exhaustion of antioxidants during neutralization of free radicals might account for lower level of TAP observed in this study. Meanwhile, excessive production of reactive oxygen species beyond the neutralization capability of the antioxidant system might be responsible for the higher OSI in the cement exposed workers. This corroborates the findings of previous 
workers that exposure to cement and cement products could cause reduced antioxidant status. Pournourmohammadi et al (2008) reported significantly lower level of antioxidants in cement exposed workers. Afaq and Abidi, (2000) also reported lower activities of GSH redox enzymes in chrysotile exposed workers. In a study conducted by Evelo and Bos (1993), it was observed that $\mathrm{SiO}_{2}$, a component of cement caused significantly lower GSH activity in those rats exposed to it after 8 days.

KIM-1, a transmembrane tubular protein, is undetectable in normal kidneys, but is markedly induced in experimental renal injury. In renal damage, the KIM-1 ectodomain is cleaved and becomes detectable in urine. Increased level of KIM-1 in different types of kidney diseases have been reported, but none of them has focused on cement exposed workers. Significantly higher level of urinary KIM-1 observed in our cement exposed workers may be the novel of this study. The increased urinary KIM-1 observed in this study could be due to cellular activation (as indicated by elevated neopterin level), inflammation and possible chronic renal damage induced by the absorbed cement particles deposited in the kidneys of the cement loaders. Since cement dust has a diameter ranging from 0.05 to $5.0 \mu$, a large percent of inhaled cement particles may be absorbed through the alveolar spaces, enter into the systemic circulation, circulate and get deposited in the visceral organs. Previous reports show that chronic exposures to aluminium content of the cement could cause increased lipid peroxidation, neurotoxicity, renal failure and anaemia (Abimbola et al, 2007; Mohammadirad A, Abdollahi, 2011). Our findings also corroborates the report of Bright et al., (1997), Costa et al. (2006) and Goldoni et al.(2006) that occupational exposure to cement dust could cause toxic effects on vital organs such as lungs, kidney and liver. A similar report by Castranova, (2004) also suggests that generation of reactive oxygen species could lead to a damaged cell membrane. Also, Ogunbileje and Akinosun (2011) reported that slightly elevated levels of urea and creatinine in cement exposed workers could suggest possibility of these workers coming down with chronic renal failure.

Neopterin is a metabolic product of macrophage activation. It is an indicator of pro-inflammatory immune status and a marker of cellular activation that is released into the circulation mainly by activated macrophages (Chandara et al, 2005). Several researchers have reported higher levels of neopterin in many diseases including tuberculosis and cancer (Chandara et al, 2005; Turgut et al, 2006; Akiibinu et al, 2009). In the present study, deposited and phagocytosed cement particles in the lungs could account for the activation of alveolar macrophages and increased neopterin release into the circulation. Since neopterin is produced predominantly by activated macrophages, increased level observed in this 
study could also confirm the excessive cellular activation induced by cement particles.

Although, the physiological roles of tumor markers remain unclear; significant expressions of these antigens have been linked with tumors and malignancies (Bast et al, 2005). To the knowledge of the authors, this study is the first to report elevated levels of 8-OHdG and CEA in cement exposed workers. This could be linked with the fact that when free radicals attack the DNA of a cell, oxidation of guanine leads to production of 8-oxo-7, 8dihydroguanine. The oxidized guanine in genomic DNA then causes transversion mutation (Shibutani et al, 1991) which could contribute to DNA damage, genomic instability and protein metabolic dysfunction. Several reports show that chronic inflammation and high free radical load cause DNA damage and gene mutation (Nelson et al, 2004; Ramanujam, 2004) which may facilitate expression of abnormal proteins. This may also lead to over-expression of tumor associated antigens with consequent shedding and appearance of the abnormal proteins in the blood (Boon et al, 1997; Carl and Edward, 2001). Since higher levels of hydrogen peroxide $\left(\mathrm{H}_{2} \mathrm{O}_{2}\right)$ are more tumorigenic and metastatic (Thalmann et al, 2000), elevated TPP in our cement loaders could contribute to enhanced CEA expression in them. Increased CEA level in this study therefore agrees with previous workers who have reported cancer of the stomach and colon in cement exposed workers. Koh et al (2011) associated stomach cancer in cement workers to cement dust containing $\mathrm{Cr}^{6+}$, while Jakobsson et al (1994) linked right side colon cancer observed in their study with longer transit time of $\mathrm{Cr}^{6+}$ in the right colon that aids longer contact. Also, since mercury, lead, nickel and chromium present in cement have cytotoxic and mutagenic effects (Kumar et al, 2008; Ritambhara et al, 2010, Yahaya et al, 2012), there is possibility of these heavy metals causing gene mutation and chemically induced tumors in cement exposed workers. Yahaya et al (2012) reported chromosomal aberrations including stickiness, c-mitosis, chromosomal bridge, chromosome fragmentation, vagrant chromosomes, bi-nucleus chromosomes and multi-polar anaphase even in a plant exposed to cement dust. Therefore, elevated levels of 8-OHdG and CEA observed in this study may serve as evidences of possible genotoxic effect of cement.

It could be concluded that metabolic disorders including excessive macrophage activation, oxidative DNA damage, kidney diseases and chemically-induced tumors are imminent in cement exposed workers.

\section{Acknowledgement}

This study is the continuation of the studies by Jakobsson et al (1994) and Koh et al (2011) who reported cancers in cement exposed workers. We appreciate the contributions of Mr. Abegunde of the Department of 
Chemistry and Biochemistry, Caleb University Lagos, Nigeria who provided technical supports.

\section{Conflicts of interest}

The authors declared that they have no competing interests.

\section{Contributions of the authors:}

MA1, MA2, TO, MA3, AA and JA designed the research. MA1, TO, MA3 did the analysis and all authors contributed and approved the final manuscript.

\section{References:}

1. Abimbola AF, Kehinde-Phillips OO and Olatunji AS. (2007). The Sagamu Cement Factory, SW Nigeria: Is the dust generated a potential health hazard. Environ. Geochem. Health; 29: 163-167.

2. Abrons HL, Petersen MR, Sanderson W, T. Engelbreg AL, Harber P. 1997. Chest radiography in Portland cement workers. J Occup Environ Med; 39:1047-54.

3. Adak MD, Adak S and Purohit KM. (2007). Ambient air quality and health hazards nearmin-cement plant. Pollution Research; 26(3): 361364.

4. Afaq F, Abidi P. (2000). N-acetyl L-cysteine attenuates oxidant mediated toxicity induced by chrysotile fibres. Toxicol Lett 117:5360.

5. Akiibinu M. O, Arinola O. G and Ogunyemi E. O. (2009). Plasma Neopterin and Peroxide levels in Pulmonary Tuberculosis Patients on Chemotherapy with or without Micronutrient Supplementation. Pakistan Journal of Medical Sciences: 25: 380-385.

6. Baby, S., Singh, N. A., Shrivastava, P., Nath, S. R., Kumar, S. S., Singh,D. and Vivek, K. 2008. "Impact of dust emission on plant vegetation of vicinity of cement plant." Environmental Engineering and Management Journal; 7(1): 31-35.

7. Bast RC Jr, Badgwell D, Lu Z, Marquez R, Rosen D, et al. (2005). New tumor markers: CA125 and beyond. Int J Gynecol Cancer 15 Suppl 3: 274-281.

8. Benzie IE, Strain JJ. (1996). The ferric reducing ability of plasma (FRAP) as a measure of antioxidant power (the FRAP assay). Annal of Biochem.; 239, 70-76.

9. Boon T, Coulie PG, Van den Eynde B. (1997). Tumor antigens recognized by $\mathrm{T}$ cells. Immunol Today 18: 267-268. 
10. Bright P, Burge PS, O'hickey SP, Gannon PF, Robertson AS, Boran A. (1997). Occupational asthma due to chrome and nickel electroplating. Thorax; 52:28-32.17.

11. Carl A.B and Edward R.A. (2001). Tumor Makers; Tietz fundamental of Clinical Chemistry. Fifth Edition., Pg. 401.

12. Castranova V. (2004). Signaling pathways controlling the production of inflammatory mediators in response to crystalline silica exposure: role of reactive oxygen/nitrogen species. Free radical biology and medicine 37:916-25.

13. Chandara I, Lalitha V, K. Silambu C, Padmapriyadarsini C, Rehman F, Iliayas S and Swaminathan I. (2005). Serum neopterin levels in HIV-infected patients with and without tuberculosis. Indian Journal of Medical Research. 121, 220-225.

14. Costa M, Klein CB. (2006). Toxicity and arcinogenicity of chromium compounds in humans. Crit Rev Toxicol; 36:155-63.

15. Dopp E, Yadav S, Ansari FA, Bhattacharya K, von Recklinghausen U, Rauen U, Rödelsperger K, Shokouhi B, Geh S, Rahman Q (2005). ROS-mediated genotoxicity of asbestos-cement in mammalian lung cells in vitro. Part Fibre Toxicol.; 2, 2-9.

16. Evelo CT, Bos RP (1993). Decreased glutathione content and glutathione S-transferase activity in red blood cells of coal miners with early stages of pneumoconiosis. Br J Ind Med; 50:633-6.

17. Fell AK, Thomassen TR, Kristensen P, Egeland T, Kongland J. 2003. Respiratory Symptoms and Ventilatory Function in Workers Exposed to Portland Cement Dust, JOEM; 45:1008- 1014.

18. George V. Taplin, Fred A. Pryan, Leonard Baurmash, Warrem N. Greene, Edward Hayes, Walter Ralsten and William Adolph. (1950) Ann. West Med. and Surg.: 4:383-390.

19. Goldoni M, Caglieri A, Poli d, Vittori MV, Corradi M, Apostoli A, et al. (2006). Determination of hexavalent chromium in exhaled breath condensate and environmental air among chrome plating workers. Anal Chim Acta 562:229-35.

20. Green GM. The JJ. (1970). Burns Amberson lecture. In defense of lung. Am. Rev. Resp. Dis.; 102: 691-703.

21. Harma M, Harma M. Erel O. (2005). Oxidative stress in women with pre-eclampsia. American Journal of Obstestrics and Gynaecology; 192 (656-657).

22. Heather, G. (2003). Effects of Air Pollution on Agricultural Crops. Ministry of Agricultural, Air Pollution on Agricultural Crops, Ontario, Canada. 
23. Hogan, C. Michael (2010). "Abiotic factor" in Encyclopedia of Earth. Emily Monosson and C. Cleveland (eds.). National Council for Science and the Environment. Washington DC.

24. Ikli,B.I., Demir, T.A., Urer, S.M., Beker, A., Akar, T. and Kalyoncu, C. (2003). Effects of chroniuum exposure from a cement factory. Environmental Research. (9):113-118.

25. Jakobsson K, Albin M, Hagmar L. (1994). Asbestos, cement, and cancer in the right part of the colon. Occup Environ Med.; 51:95101.

26. Kalacic I. (1973). Chronic nonspecific lung disease in cement workers. Arch Environ Health; 26:78-83.

27. Koh D, Kim T, Jang S, and Ryu H. (2011). Cancer Mortality and Incidence in Cement Industry Workers in Korea. Saf Health Work. 2(3): 243-249.

28. Kopnin PB, Kravchenko IV, Furalyov VA, Pylev LN, Kopnin BP. (2004). Cell type-specific effects of asbestos on intracellular ROS levels, DNA oxidation and G1 cell cycle checkpoint. Oncogene; 23, 8834-40.

29. Kumar, S. S., Singh, N. A.,Kumar, V., Sunisha, B., Preeti, S., Deepali, S. and Nath, S. R (2008). Impact of dust emission on plant vegetation in the vicinity of cement plant." Environmental Engineering and Management Journal. 7(1): 31-35.

30. Mohammadirad A, Abdollahi M. (2011). A systematic review on oxidants/antioxidant imbalance in aluminum toxicity. Int $\mathrm{J}$ Pharmacol.; 7:12-21.

31. Nelson WG, De Marzo AM, DeWeese TL, Isaacs WB (2004). The role of inflammation in the pathogenesis of prostate cancer. J Urol 172: S6-11.

32. Ogunbileje, J. O. and Akinosun, O. M. (2011). Biochemical and haematological profile in Nigerian cement factory workers. Res. J. Environ. Toxicol. 5: 133-140.

33. Pournourmohammadi S., Khazaeli P, Eslamizad A., Tajvar A, Mohammadirad A. and Abdollahi M. (2008). Study on the oxidative stress status among cement plant workers. Hum. Exp. Toxicol. 27:463-469.

34. Ramanujam M.D (2004). Free radicals and antioxidants - current status. www.meclindia.net/article/anitoxidantsasp

35. Ritambhara, T. and Kumar, G. (2010). Genetic loss through heavy metal induced chromosomal stickiness in Grass pea. Plant Genetics Laboratory, Department of Botany, University of Allahabad, Allahabad-211002, India. 
36. Schwartz, J. (1994). Air pollution and daily mortality: A review and meta analysis. Environmental Research,; (64): 36-52.

37. Shi X, Dalal NS, Kasprzak KS. (1993). Generation of free radicals from hydrogen peroxide and lipid hydroperoxides in the presence of Cr(III). Arch Biochem Biophys 302:294-299.

38. Shibutani S, Takeshita M, Grollman AP. (1991). Insertion of specific bases during DNA synthesis past the oxidation-damaged base 8oxodG. Nature 349: 431-434.

39. Sivicommar, R., Jayabalou, R., Subrahmanyam, Y.V., Jothikumar, N. and Swarnalatha, S. (2001). Air pollution in stone crushing industry and associated health effect. Indian journal of environmental health; (4):169-73.

40. Thalmann GN, Sikes RA, Wu TT, Degeorges A, Chang SM, Ozen M, Pathak S, Chung LW, (2000). LNCaP progression model of human prostate cancer: androgen independence and osseous metastasis. Prostate. 44(2): 91-103; 44(2).

41. Torreilles J, Guerin MC (1990). Nickel(II) as a temporary catalyst for hydroxyl radical generation. FEBS Lett; 272:58-60.

42. Turgut T, Akbulut H, Devesi F, Kacar C, Muz MH.(2006). Serum interleukin-2- and neopterin levels as useful markers for treatment of active pulmonary tuberculosis. Tohoku Journal of Experimental Medicine. 209 (4) 321- 328.

43. Valavanidis A, Fiotakis K, and VLachogianni T. (2008). Airborne particulate matters and human health: toxicological assessment and importance of size and composition of particles for oxidative damage and carcinogenic mechanisms”. J. Environ. Sci. health C. Environ. Carcinog. Ecotoxicol. Rev. 26(4) 339-362.

44. Varshney R and Kale (1990). Effect of calmodulin antagonist on radiation-induced lipid peroxidation in microsomes. International Journal of Radiology and Biology.; 58: 733-743.

45. Yahaya, T. Okpuzor, J. and Oladele, E. O. (2012). Investigation of Cytotoxicity and Mutagenicity of Cement Dust Using Allium cepa Test, Res. J. Mutagenesis, 1: 10-18.

46. Zeleke, Z., Moen, B. and Bratveit, M. (2010). "Cement dust exposure and acute lung function: A cross shift study." BMC Pulmonary Medicine; 10(1): 19. 